PeAKall, R. and P. E. SMouse (2006): GENALEX 6: genetic analysis in Excel. Population genetic software for teaching and research. Molecular Ecology Notes 6: 288-295.

R Development CoRe Team (2011): R: A language and environment for statistical computing. $\mathrm{R}$ Foundation for Statistical Computing, Vienna, Austria. ISBN 3-90005107-0, URL http://www.R-project.org/.

RAYMOND, M. and F. RousseT (1995): Genepop (version 1.2): population genetics software for exact tests and ecumenicism. Journal of Heredity 86: 248-249.

WANG, X. H., X. H. MA, G. Q. Jin, L. Y. ChEN and Z. C. ZHOU (2011): Variation pattern of individual types and wood characters in natural stands of Schima superba. Scientia Silvae Sinicae 47: 133-139.
XU, W., H. Wang, G. X. Zhou and X. S. YaO (2010): Two new 8-O-4'-type lignans from the stem of Schima super$b a$ and their cell growth inhibitory activities against human cancer cell lines. Journal of Asian Natural Products Research 12: 874-878.

YANG, S. X., H. DENG and M. S. LI (2008): Manganese uptake and accumulation in a woody hyperaccumulator, Schima superba. Plant Soil and Environment 54: 441-446.

Zhang, P., G. Q. Jin, Z. C. Zhou, L. Yu and H. H. FAN (2004): Provenance difference and geographic variation pattern for seedling trait of Schima superba. Forest Research 17: 192-198.

\title{
Genetic status of Norway spruce (Picea abies) breeding populations for northern Sweden
}

\author{
By P. Androsiuk ${ }^{1,4)}$, A. Shimono ${ }^{1)}$, J. Westin ${ }^{2)}$, D. Lindgren ${ }^{3)}$, A. Fries ${ }^{3)}$ and X.-R. Wang ${ }^{\left.1),{ }^{*}\right)}$
}

(Received 29 $9^{\text {th }}$ October 2012)

\begin{abstract}
Efficient use of any breeding resources requires a good understanding of the genetic value of the founder breeding materials for predicting the gain and diversity in future generations. This study evaluates the distribution of genetic variation and level of relatedness among and within nine breeding populations of Norway spruce for Northern Sweden using nuclear microsatellite markers. A sample set of 456 individuals selected from 140 stands were genotyped with 15 SSR loci. Over all loci each individual was identified with unique multilocus genotype. High genetic diversity (average $H_{e}=0.820$ ) and low population differentiation $\left(F_{S T}=0.0087\right)$ characterized this material. Although low in $F_{S T}$, the two northernmost populations were clustered as a distinct group diverged from the central populations. The population differentiation pattern corresponds well with the post glacial migration history of Norway spruce and the current gene flow and human activity in the region. The average inbreeding coefficient was 0.084 after removal loci with high frequency of null alleles. The estimated
\end{abstract}

1) Department of Ecology and Environmental Science, Umeå University, SE-901 87 Umeå, Sweden.

$\left.{ }^{2}\right)$ Forestry Research Institute of Sweden (SkogForsk), SE-918 21 Sävar, Sweden.

3) Department of Forest Genetics and Plant Physiology, UPSC, Swedish University of Agricultural Sciences, SE-901 83 Umeå, Sweden.

${ }^{4)}$ Department of Genetics, Faculty of Biology and Biotechnology, University of Warmia and Mazury in Olsztyn, Poland.

*) Corresponding author: Dr. XIAO-RU WANG. Department of Ecology and Environmental Science. Umeå University, SE-901 87 Umeå, Sweden. Phone: +46-90-7869955, Fax: +46-90-7866705. E-mail: xiao-ru.wang@emg.umu.se relatedness of the trees gathered in the breeding populations was very low (average kinship coefficient 0.0077) and not structured. The high genetic variation and low and not structured relatedness between individuals found in the breeding populations confirm that the Norway spruce breeding stock for northern Sweden represent valuable genetic resources for both long-term breeding and conservation programs.

Key words: breeding stock, genetic diversity, long-term breeding, population subdivision, relatedness.

\section{Introduction}

Norway spruce (Picea abies (L.) Karst.) is one of the dominant forest species in Scandinavia. In Sweden, the production forests are based mainly on two conifer trees, Norway spruce and Scots pine (Pinus sylvestris L.), among which Norway spruce is economically the most important. The productivity of Norway spruce forests is supported by using improved and certified seed and seedling materials, and backed up by long-term breeding programmes, which at the same time serve gene conservation purpose. Intense breeding and seed orchard programs are developed for this species in Sweden (LiNDGREN et al., 2008; LINDGREN, 2009). The Swedish spruce breeding program considers the clinal variation in photoperiod and temperature, and thus divides the country from north to south into 20 partly overlapping, latitudinally distributed breeding populations (also called breeding zones) (SKOGFORSK, 2011). This subdivision considers the geographic origin and the target climate area, expressed with heat sum (altitude) and light climate (latitude), of each breeding population. 
The division and selection of target climate areas are based on the field performance in progeny and clonal tests. Each breeding population consists at least 50 tested genotypes selected from natural stands (SkOGForSK, 2011). These selections serve as a founder stock for longterm breeding and gene conservation program. A deployment material (e.g. seed orchard) drawn from the breeding stock typically is derived from four adjacent breeding populations. This study comprised the nine northernmost of these populations; jointly they represent almost half of the Swedish range of the species (Fig. 1). Knowledge of the genetic diversity, differentiation, and the relatedness in the founder breeding population is essential for efficient use of the breeding resources. Such knowledge is valuable for predictions of the consequences of tree breeding programs, e.g. on genetic diversity or risks for building up inbreeding and relatedness over generations.

Picea abies with its wide natural distribution covering most of continental Europe is characterized by high genetic diversity and low among population differentiation (MÜLlER-STARCK et al., 1992). However, toward the north in Fennoscandia and adjacent areas, significant decrease in allelic richness and genetic diversity is reported, which is assumed to be associated with smaller effective population size caused by local reduction in seed and pollen production and increased inbreeding (TollefsRud et al., 2009). The decrease of outcrossing rate and lower diversity of available gamets within population could be a result of low population density, as it is shown for peripheral populations of Pinus sylvestris (Robledo-ARnUncio et al., 2004), Pinus strobus (RAJORA et al., 2002) and Picea sitchensis (Mimura and AitKen, 2007). In such populations, assortative mating mediated by local pollen flow between close relatives, could build up relatedness within local populations. Information about coancestry is important for any breeding program as it impacts upon the effectiveness of the selection. Long-term breeding aims at an appropriate balance between achieving high genetic gain and managing coancestry at a level that results in more sustainable genetic gain. This knowledge is even more relevant for spruce breeding for northern Sweden if there is a risk of increased relatedness in the local populations and of the increasing problem of vanishing of Norway spruce natural forest by widely transferred plantings in large part of the area.

In this study, we analysed the distribution of genetic variation in the founder breeding populations for northern and central Sweden using nuclear microsatellite (SSR) markers. The primary aim of the present study was to provide an overview on the genetic structure and relatedness in the Swedish breeding populations of Norway spruce. In addition, since these accessions also represent natural population sampling, our analysis would also serve as a natural population structure investigation for the northern range of the species, a region that has not been extensively sampled in early studies. Although plus trees were selected, considering the low heritability of the phenotypes and that the SSR markers are assumed to be neutral, it is unlikely the selected trees do not reflect the conditions in natural forests. The founders for southern breeding populations are of mixed (some non-native) origins, and the documentation of their origins are often imprecise (Dag Lindgren and Johan Westin personal communication). Analysis of these southern breeding stocks should largely reflect human activities rather than natural history and native resources of the species in Sweden. For this reason they are not included in the present investigation. In this study, we addressed the following questions: (i) what is the level of genetic diversity and differentiation of Norway spruce in central and northern Sweden? (ii) what is the level of relatedness among the funders of Norway spruce breeding populations? and (iii) what is the implication for the long-term spruce breeding in Sweden?

\section{Materials and Methods}

\section{Study site and sampling}

We sampled 456 trees from Skogforsk Norway spruce archive at Sävar (outside Umeå, Sweden), which holds the main collection of northern Swedish spruce founder trees. These trees are from 140 stands in nine breeding populations (Fig. 1). The nine breeding populations cover northern to central Sweden with latitudinal range from $61^{\circ} 22^{\prime} \mathrm{N}$ to $67^{\circ} 55^{\prime} \mathrm{N}$. The number of trees from each stand ranged from 1 to 12 , and each breeding population was represented by 51 to 56 individuals, with exception for population No. 9, which was represented by 31 trees.

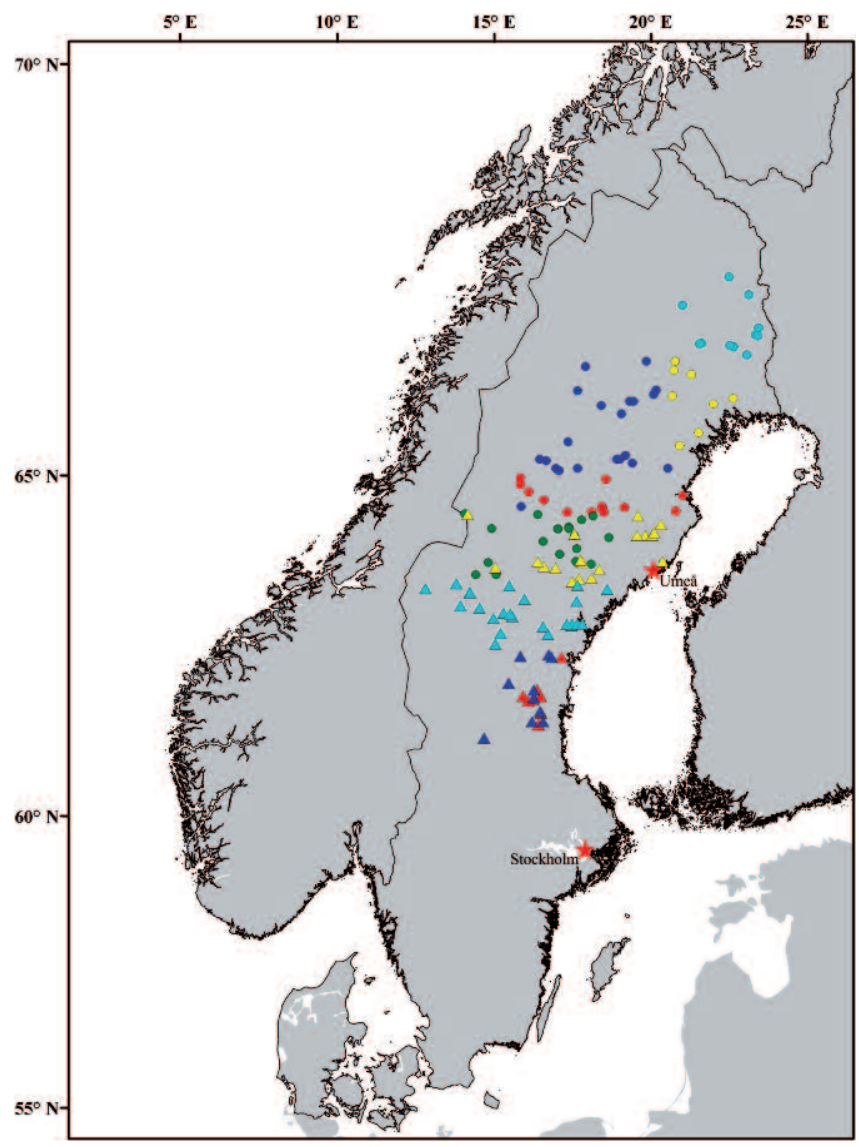

Figure 1. - Geographic distribution of the 140 sampled stands of Norway spruce that represent nine breeding populations for Northern Sweden. Each breeding population is represented by a different color. 
In this study trees from each breeding population are regarded as a population. Needles were collected in the spring 2010 and stored at $-20^{\circ} \mathrm{C}$ until DNA extraction.

\section{DNA extraction and SSR genotyping}

Genomic DNA was extracted from needles of each individual tree using an E.Z.N.A ${ }^{\mathrm{TM}}$ SP plant DNA mini kit (OMEGA Bio-tek). We screened a large number of dinucleotide and trinucleotide microsatellite (SSR) markers for our spruce materials, from which 15 that showed high polymorphism and easy scoreable alleles were selected. Genotyping was conducted for the following SSR loci: SpAG2, SpAGG3, SpAGC1, SpAGC2, SpAGD1, SpAC1H8 and SpAC1F7 (PFEIFFer et al., 1997), paGB3 and paGB5 (BESNARD et al., 2003), EAC6B03, EAC7H07 and EAC2C08 (ScOTTI et al., 2002b), EATC2B02 and EATC2G05 (ScotTi et al., 2002a) and UAPgAG150A (HIDGETTS et al., 2001).

For SSR amplification, polymerase chain reaction (PCR) was performed in $10 \mu \mathrm{l}$ reaction volume containing 1 x PCR buffer, $2.0 \mathrm{mM}$ of $\mathrm{MgCl}_{2}, 0.2 \mu \mathrm{M}$ of each dNTP, $0.12 \mu \mathrm{M}$ of each primer, 0.15 unit of Top Taq polymerase (QIAGEN) and 10-30 ng of template DNA. Loci SpAG2, SpAGG3, SpAGC1, SpAGC2, SpAC1F7, paGB5, EATC2B02, EATC2G05 and UAPgAG150A were amplified using the following protocol: an initial denaturation $\left(3 \mathrm{~min}\right.$ at $\left.94^{\circ} \mathrm{C}\right)$, eight cycles of touchdown $\left(30 \mathrm{~s}\right.$ at $94^{\circ} \mathrm{C}$, $30 \mathrm{~s}$ at $64^{\circ} \mathrm{C}$ to $56^{\circ} \mathrm{C}$ with $1^{\circ} \mathrm{C}$ decrement per cycle, $30 \mathrm{~s}$ at $\left.72{ }^{\circ} \mathrm{C}\right), 25$ cycles of amplification $\left(30 \mathrm{~s}\right.$ at $94^{\circ} \mathrm{C}, 30 \mathrm{~s}$ at $56^{\circ} \mathrm{C}$ and $30 \mathrm{~s}$ at $72^{\circ} \mathrm{C}$ ) and final extension (10 min. at $72^{\circ} \mathrm{C}$ ). Loci EAC6B03 and EAC2C08 were amplified using the same protocol but with a touchdown from $58^{\circ} \mathrm{C}$ to $50^{\circ} \mathrm{C}$, for loci SpAGD1 and SpAC1H8 the touchdown temperature was from $62^{\circ} \mathrm{C}$ to $57^{\circ} \mathrm{C}$, whereas for paGB3 from $60^{\circ} \mathrm{C}$ to $50^{\circ} \mathrm{C}$. Locus EAC7H07 was amplified under the following conditions: $3 \mathrm{~min}$ at $94^{\circ} \mathrm{C}, 30$ cycles of $30 \mathrm{~s}$ at $94^{\circ} \mathrm{C}, 30 \mathrm{~s}$ at $62^{\circ} \mathrm{C}, 30 \mathrm{~s}$ at $72^{\circ} \mathrm{C}$ and a final extension at $72^{\circ} \mathrm{C}$ for $10 \mathrm{~min}$.

The fluorescently labelled PCR products together with size marker (size standard-400, Beckman-Coulter) were resolved on a CEQ8000 capillary sequencer (BeckmanCoulter). Allele identification and genotyping were performed using the CEQ8000 Fragment Analysis software (Beckman-Coulter). All peaks and binning were manually checked to minimize genotyping error.

\section{Data analyses}

For each SSR locus, and in each population, the total number of alleles detected $\left(N_{t}\right)$, the average number of alleles per locus $\left(N_{a}\right)$, allelic richness $\left(A_{R}\right)$, the effective number of alleles $\left(N_{e a}=1 / 1-H_{e}\right)$, the number of private alleles by breeding population $\left(N_{p a}\right)$, the observed $\left(H_{o}\right)$ and expected $\left(H_{e}\right)$ heterozygosity, and inbreeding coefficient $\left(F=1-H_{o} / H_{e}\right)$ were estimated. The allelic richness within each breeding population was calculated in SWAP v.0.9 (http://www.unimarburg.de/fb17/fachgebiete/naturschutz/naturschutzbiologie/downloads). Inbreeding coefficients were estimated using ARLEQUIN 3.5 (EXCOFFIER et al., 2005). The other diversity measures were calculated using GenAlEx 6.2 (PEAKALL and SMouse, 2006).
Genotypic disequilibrium for each pair of loci in each population was tested using GENPOP 4.0 (ROUSSET, 2008) with a sequential Bonferroni correction (RICE, 1989). Hardy-Weinberg Equilibrium (HWE) was tested using the exact test (GUO and THOMPSON, 1992) based on Markov chain iterations as implemented in ARLEQUIN. $F$-statistics (WEIR and COCKERHAM, 1984) of genetic divergence among populations $\left(F_{S T}\right)$ were estimated using GENPOP 4.0. Null allele frequencies for each microsatellite locus and each population were estimated following the expectation maximum algorithm of (DEMPSTER et al., 1977) using FreeNA (CHAPUIS and EsToup, 2007). To examine the potential effect of null alleles on genetic differentiation the $F_{S T}$ values were also calculated by excluding null allele (ENA) in FreeNA. Analysis of molecular variance (AMOVA) partitioning the total genetic variation among breeding populations, among individuals within breeding populations and within individuals was performed using ARLEQUIN.

To investigate patterns of genetic subdivision, we applied: (i) principal component analysis (PCA) on allele frequencies, and (ii) Bayesian methods implemented in BAPS 5.2 (CORANDER et al., 2008) and STRUCTURE 2.3.1 (PRITCHARD et al., 2000). PCA was run using the STATISTICA 7.1 software (STATSOFT, 2005). Both BAPS and STRUCTURE attempt to reveal the true number of genetic clusters in a sample of individuals by placing individuals or predefined groups in $\mathrm{K}$ clusters with optimal Hardy-Weinberg and gametic phase equilibrium within cluster. $\mathrm{K}$ was not chosen in advance, but varied within a reasonable range. For the first run of BAPS the individual clustering option was chosen, but this resulted in an unreasonably high number of clusters. For that reason, we used the number of breeding populations as units in the analysis. $K$ was set from 1 to 10 with ten replicates for each $\mathrm{K}$ in five independent runs. With STRUCTURE, we conducted 10 replicate runs for each value of $\mathrm{K}$ from 1 to 10 . Each run consisted of burn-in of 50000 iterations, followed by data collection over 200000 iterations, with and without prior information on the sampling location. The most likely number of clusters $(\mathrm{K})$ was evaluated using $\Delta \mathrm{K}$ method (EvANNO et al., 2005), in which $\Delta \mathrm{K}$ was an ad hoc statistic based on the rate of change in the log probability of data between successive $K$ values; the chosen value of $K$ was that which gave the highest value of $\Delta \mathrm{K}$.

Recent population history was inferred by examining the departure from drift-mutation equilibrium based on allele frequencies using the program BOTTLENECK ver. 1.2.02 (CORNUET and LUIKART, 1996; PIRY et al., 1999) for each population. In populations that have experienced a recent reduction in their effective population size, the $H_{e}$ becomes larger than the heterozygosity expected at mutation-drift equilibrium. The significance of potential bottleneck was estimated using one-tailed Wilcoxon sign rank test for heterozygosity excess, under infinite allele model (IAM) and the stepwise mutation model (SMM).

To describe how relatedness is structured within and between breeding populations, multilocus kinship coeffi- 
cient $F_{i j}$ (LOISELLE et al., 1995) was estimated. The calculation of $F_{i j}$ values for pairs of individuals within and between breeding populations were performed in SPAGeDi 1.3 (HARDY and VEKEMANS, 2002). To test whether $F_{i j}$ values vary between analysed breeding populations, the Fischer's LSD multiple range test was performed. The correlation of physical distance and the relatedness between individuals was estimated by Mantel test with 1000 random permutations of the relationship between the matrix of $F_{i j}$ values and that of logarithm of geographic distance between sampling sites, using ARLEQUIN.

\section{Results}

\section{Genetic diversity}

Over the whole sample set of 456 individuals, a total of 369 different alleles were detected at the 15 polymorphic SSR loci with an average of 24.6 alleles per locus (Table 1). The number of alleles per locus ranged from 9 (pgGB5) to 58 (SpAGD1). The genetic diversity $\left(H_{e}\right)$ among loci ranged from 0.566 at SpAC1F7 to 0.941 at EAC7H07 (Table 1). The estimated null allele frequencies $\left(P_{n}\right)$ ranged from 0.0014 at SpAGG3 to 0.2495 at SpAGC2. 10 of the 15 analyzed loci had very low null allele frequency $(0.0749-0.0014)$, but the other five loci (SpAGC2, EAC6B03, SpAC1F7, SpAGD1 and UAPgAG150A) had $P_{n}$ values close or higher than $10 \%$. Over the 15 loci, each of the 456 individuals was identified with a unique multilocus genotype. A total of 945 tests for genotypic disequilibrium between pairs of the 15 loci were performed, of which only five tests were significant $(p<0.05)$ with sequential Bonferroni correction $(k=9)$. Thus, all loci were considered to be genetically independent when analysed further.

At population level, 57 private alleles were found at 14 loci, distributed in all nine breeding populations at very low overall frequencies (up to 0.027 ). There was no geographic structure in the private allele distribution and they seem to occur randomly. The allelic richness $\left(A_{R}\right)$ and effective number of alleles $\left(N_{e a}\right)$ estimated for each breeding population ranged from 21.47 (population No. 1) to 17.2 (population No. 9) and from 8.34 (population No. 1) to 6.42 (population No. 7), respectively. The highest values of $N_{e a}$ were found in the two northernmost provenances (population Nos. 1 and 3), and allelic richness was also high in this region. The genetic diversity $\left(H_{e}\right)$ followed the same pattern: the highest $H_{e}$ estimates $(0.837$ and 0.833$)$ occurred in the northern breeding populations No. 1 and 3, respectively, whereas the lowest $H_{e}=0.803$ value was described for population No. 7 (Table 2).

The single-locus tests for Hardy-Weinberg Equilibrium (HWE) in each breeding population showed significant $(p<0.05)$ departure in 67 out of 135 cases, distributed over all 15 loci, and 53 of them remained significant after sequential Bonferroni correction $(k=15)$. All the departures were due to homozygote excess. The average value of inbreeding coefficient $(F)$, over loci and breeding populations, was 0.189 and ranged from 0.158 for population No. 7 to 0.210 for population No. 2 (Table 2 ). All the $F$ values were significantly positive. After removal, the five loci with the highest frequency of null alleles (SpAGC2, EAC6B03, SpAC1F7, SpAGD1 and

Table 1. - Diversity measures at the 15 SSR loci in the nine Norway spruce breeding populations sampled in this study.

\begin{tabular}{lccccccc}
\hline \multicolumn{1}{c}{ Locus } & No. alleles & $H_{o}$ & $H_{e}$ & $F_{i s}$ & $F_{s t}$ & $F_{s t}($ ENA $)$ & $P_{n}$ \\
\hline EAC2C08 & 28 & 0.8354 & 0.8932 & $0.0640^{*}$ & 0.0008 & 0.0011 & 0.0283 \\
EAC7H07 & 44 & 0.8777 & 0.9412 & $0.0692^{*}$ & 0.0037 & 0.0043 & 0.0301 \\
EATC2G05 & 17 & 0.7075 & 0.8614 & $0.1758^{*}$ & 0.0073 & 0.0079 & 0.0733 \\
pgGB5 & 9 & 0.7588 & 0.7539 & -0.0057 & 0.0144 & 0.0145 & 0.0097 \\
SpAC1H8 & 28 & 0.6829 & 0.8200 & $0.1705^{*}$ & 0.0083 & 0.0093 & 0.0749 \\
SpAGC1 & 23 & 0.7150 & 0.7609 & $0.0640^{*}$ & 0.0129 & 0.0131 & 0.0264 \\
SpAGD1 & 58 & 0.5874 & 0.9326 & $0.3782^{*}$ & 0.0081 & 0.0054 & 0.1731 \\
UAPgAG150A & 14 & 0.5890 & 0.7687 & $0.2342^{*}$ & 0.0192 & 0.0185 & 0.0971 \\
EATC2B02 & 19 & 0.5635 & 0.6715 & $0.1628^{*}$ & 0.0099 & 0.0110 & 0.0644 \\
paGB3 & 11 & 0.7329 & 0.7616 & 0.0389 & 0.0057 & 0.0057 & 0.0179 \\
SpAC1F7 & 17 & 0.2946 & 0.5663 & $0.4686^{*}$ & 0.0169 & 0.0210 & 0.1851 \\
SpAG2 & 21 & 0.7867 & 0.8992 & $0.1202^{*}$ & 0.0053 & 0.0056 & 0.0530 \\
SpAGG3 & 26 & 0.9366 & 0.9252 & -0.0130 & 0.0006 & 0.0006 & 0.0014 \\
EAC6B03 & 26 & 0.5141 & 0.8811 & $0.4216^{*}$ & 0.0062 & 0.0076 & 0.1949 \\
SpAGC2 & 28 & 0.3891 & 0.8587 & $0.5480^{*}$ & 0.0174 & 0.0123 & 0.2495 \\
\hline All loci & 24.6 & 0.6647 & 0.8197 & 0.1889 & 0.0087 & 0.0086 & - \\
\hline
\end{tabular}

$H_{o}=$ observed heterozygosity; $H_{e}=$ expected heterozygosity; $F_{i s}=$ fixation index, computed as in WEIR and COCKERHAM (1984), values significantly different from zero are indicated with * $(* p<0.001) ; F_{s t}=$ genetic divergence among populations, computed as in WEIR and Cockerham (1984); $F_{s t}(E N A)=F_{S T}$ using the excluding null allele (ENA) method by CHAPUis and Estoup (2007); $P_{n}=$ null allele frequency estimated as in DeMPster et al. (1977). 
Table 2. - Genetic diversity in the nine breeding populations and in the two groups defined by BAPS clustering.

\begin{tabular}{lccccccccccc}
\hline & $\begin{array}{c}\text { Breeding } \\
\text { population }\end{array}$ & $N$ & $N_{t}$ & $N_{a}$ & $N_{p}$ & $N_{e a}$ & $A_{R}$ & $H_{o}$ & $H_{e}$ & $\boldsymbol{F}$ & $\boldsymbol{F}^{*}$ \\
\hline & Population 1 & 54 & 234 & 15.60 & 6 & 8.34 & 21.47 & 0.672 & 0.837 & $0.197^{* *}$ & $0.090^{* *}$ \\
& Population 2 & 52 & 232 & 15.47 & 4 & 7.48 & 20.53 & 0.643 & 0.816 & $0.210^{* *}$ & $0.074^{* *}$ \\
& Population 3 & 51 & 241 & 16.27 & 12 & 7.65 & 20.53 & 0.669 & 0.833 & $0.194^{* *}$ & $0.067^{*}$ \\
& Population 4 & 51 & 219 & 14.60 & 7 & 6.54 & 19.40 & 0.650 & 0.807 & $0.194^{* *}$ & $0.107^{* *}$ \\
& Population 5 & 54 & 224 & 14.93 & 3 & 6.51 & 19.40 & 0.673 & 0.804 & $0.165^{* *}$ & $0.086^{* *}$ \\
& Population 6 & 53 & 227 & 15.13 & 5 & 7.36 & 19.47 & 0.675 & 0.830 & $0.187^{* *}$ & $0.101^{* *}$ \\
& Population 7 & 54 & 218 & 14.53 & 7 & 6.42 & 19.27 & 0.678 & 0.803 & $0.158^{* *}$ & $0.076^{* *}$ \\
& Population 8 & 56 & 240 & 16.00 & 6 & 7.56 & 21.00 & 0.661 & 0.822 & $0.195^{* *}$ & $0.070^{* *}$ \\
& Population 9 & 31 & 195 & 13.00 & 7 & 7.42 & 17.20 & 0.659 & 0.825 & $0.201^{* *}$ & $0.081^{* *}$ \\
\hline & All & 456 & - & 15.06 & 57 & 7.25 & - & 0.665 & 0.820 & $0.189^{* *}$ & $0.084^{* *}$ \\
\hline BAPS & Cluster 1 & 105 & 282 & 18.80 & 18 & 8.318 & 18.53 & 0.670 & 0.836 & $0.197^{* *}$ & $0.079^{* *}$ \\
clustering & Cluster 2 & 351 & 349 & 23.40 & 39 & 7.585 & 23.27 & 0.663 & 0.819 & $0.189^{* *}$ & $0.087^{* *}$ \\
\hline
\end{tabular}

$N=$ No. of individuals; $N_{t}=$ No. of different alleles (total) revealed in particular population; $N_{a}=$ No. of alleles per locus; $N_{p}=$ No. of private alleles; $N_{e a}=$ No. of effective alleles; $A_{R}=$ allelic richness; $H_{o}=$ observed heterozygosity; $H_{e}=$ expected heterozygosity; $F=$ inbreeding coefficient $=(\mathrm{He}-\mathrm{Ho}) / \mathrm{He}=1-(\mathrm{Ho} / \mathrm{He})($ significant for $* * p<0.001 ; * p<0.01) ; F^{\#}=$ inbreeding coefficient calculated after exclusion of five loci with the highest frequency of null alleles (SpAGC2, EAC6B03, SpAC1F7, SpAGD1 and UAPgAG150A).

UAPgAG150A), the calculation of $F$ values was repeated and new estimates $\left(F^{\#}\right)$ were systematically decreased in all populations with a range of 0.067 (population No. 3) to 0.107 (population No. 4) and an average value of 0.084 (Table 2). This pattern suggests that the presence of null alleles had a strong effect on fixation index in these spruce populations, and removal of them decreased the index from 0.189 to 0.084 .

\section{Geographic structure}

Genetic differentiation among the nine breeding populations was low $\left(F_{S T}=0.0087, \mathrm{SD}=0.0059\right)$ and did not change much after ENA correction $\left(F_{S T}(\mathrm{ENA})=0.0086\right)$ (Table 1). The pairwise $F_{S T}$ values ranged from -0.0018 to 0.0206 (Table 3), the highest value was obtained between the northernmost population No. 1 and population No. 7 from central Sweden. Slightly lower values of pairwise $F_{S T}(0.0188$ and 0.0185$)$ described the relationship between population No. 1 and 4 and 5, respectively.

Bayesian methods implemented in the STRUCTURE failed to reveal genetic structure among the analysed breeding populations - all populations were ascribed to the same, one cluster. The BAPS analysis, on the other hand, identified two clusters, the two most northern populations (Nos. $1 \& 3$ ) were one group and all the other seven populations another group. The degree of genetic divergence between these two clusters is described by $F_{S T}=0.0128$. Genetic diversity indices for these two BAPS clusters were similar (Table 2). For inbreeding coefficient $\left(F^{\#}\right)$, after correction for null alleles, a slightly higher value was observed for cluster 2 . AMOVA on the nine breeding populations revealed that $0.87 \%$ of the total variance was explained by differences among breeding populations. When AMOVA was performed on the BAPS clusters the difference between those two clusters explained $1.28 \%$ of total variance. These results agree well with the $F_{S T}$ measurements.

Analysis of principal components based on allele frequencies indicated that $67.03 \%$ of variation is explained by the first three components $(35.36 \%, 22.09 \%$ and $9.58 \%$, respectively). Figure 2 illustrates the projection of the breeding populations on these first three axes.

Table 3. - Pairwise $F_{s t}$ values between the nine breeding populations.

\begin{tabular}{lccccccccc}
\hline & Pop1 & Pop 2 & Pop 3 & Pop 4 & Pop 5 & Pop 6 & Pop 7 & Pop 8 & Pop 9 \\
\hline Pop 1 & - & & & & & & & & \\
Pop 2 & 0.0070 & - & & & & & & & \\
Pop 3 & 0.0004 & 0.0060 & - & & & & & & \\
Pop 4 & 0.0188 & 0.0046 & 0.0163 & - & & & & & \\
Pop 5 & 0.0185 & 0.0072 & 0.0166 & -0.0005 & - & & & & \\
Pop 6 & 0.0140 & 0.0056 & 0.0110 & 0.0003 & 0.0023 & - & & & \\
Pop 7 & 0.0206 & 0.0080 & 0.0185 & -0.0018 & -0.0005 & 0.0002 & - & & \\
Pop 8 & 0.0166 & 0.0057 & 0.0131 & 0.0052 & 0.0058 & 0.0040 & 0.0068 & - & \\
Pop 9 & 0.0157 & 0.0095 & 0.0119 & 0.0098 & 0.0141 & 0.0100 & 0.0155 & 0.0020 & - \\
\hline
\end{tabular}




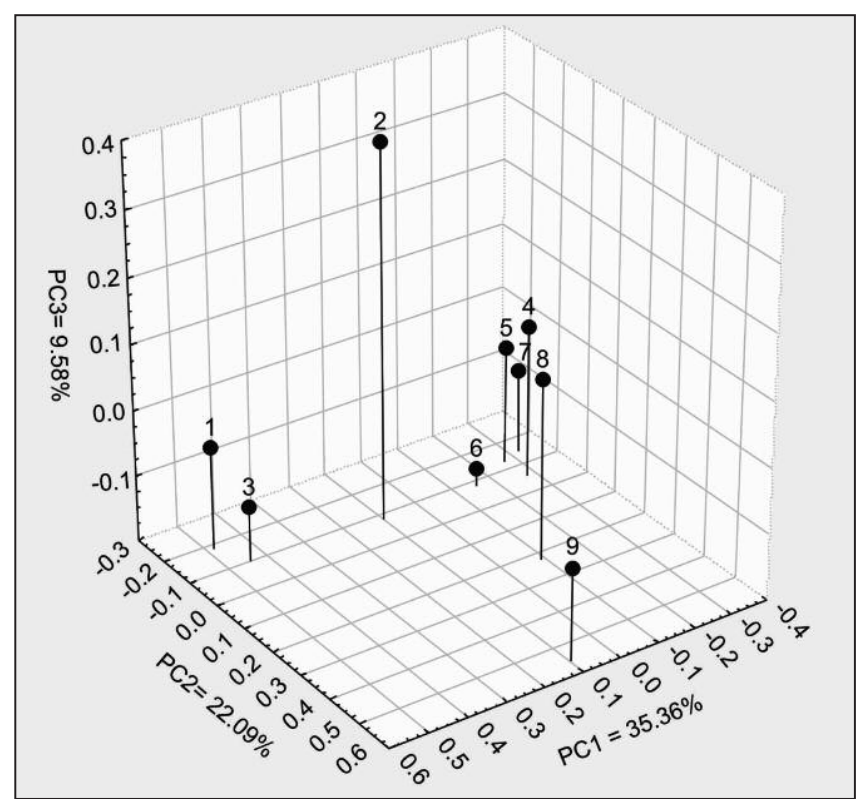

Figure 2. - Principal component analysis (PCA) based on allele frequencies of the nine breeding populations.

The grouping revealed by PCA is similar to that of BAPS. Breeding populations No. 1 and 3 were close together and departed from the others along PC1, populations No. 4-7 from the Central Sweden formed one tightly spaced cluster. The two most southern populations No. 8 and 9 diverged along PC2 from the other populations, whereas population 2 from the northwest departed from the others along PC3. This pattern of population clustering did not change when five loci (SpAGC2, EAC6B03, SpAC1F7, SpAGD1 and UAP-
Table 4. - Results of Bottleneck test in the nine breeding populations under IAM and SMM models.

\begin{tabular}{lccc}
\hline & Breeding populations & IAM & SMM \\
\hline & Population 1 & $\mathbf{0 . 0 0 5 1}$ & 0.9993 \\
Population 2 & 0.1039 & 0.9998 \\
& Population 3 & $\mathbf{0 . 0 4 1 6}$ & 0.9999 \\
& Population 4 & 0.3599 & 0.9987 \\
& Population 5 & 0.2622 & 0.9998 \\
& Population 6 & $\mathbf{0 . 0 0 1 7}$ & 1.00 \\
& Population 7 & 0.3193 & 0.9996 \\
& Population 8 & 0.1262 & 0.9996 \\
BAPS & Population 9 & $\mathbf{0 . 0 3 1 9}$ & 0.9635 \\
clustering & Cluster 1 & $\mathbf{0 . 0 0 5 1}$ & 0.9998 \\
\hline
\end{tabular}

Bold values indicate a significant excess $(p<0.05)$ of gene diversity as compared with the gene diversity expected at the mutation drift equilibrium. IAM - infinite allele model; SMM - stepwise mutation model.

gAG150A) with high frequency of null allele were removed from the data set.

Bottleneck test conducted on all loci (Table 4) indicated that four populations (No. 1, 3, 6, and 9) were found to be not at mutation-drift equilibrium under IAM, which may denote evidence of a recent bottleneck in these areas. Under SMM, however, no signature of significant bottleneck in any of the breeding populations was detected (Table 4). The bottleneck test was also conducted on the groups distinguished by BAPS; significant excess of gene diversity in relation to allelic diversity was found only under IAM model for cluster 1, which

Table 5. - Multilocus kinship coefficient estimates $\left(F_{i j}\right)$ calculated between individuals in each breeding population, presented as minimum, maximum, average value with its standard deviation (SD) and coefficient of variation (SD/average).

\begin{tabular}{lcccccc}
\hline & \multicolumn{4}{c}{$F_{i j}$ kinship coefficient } & Coefficient \\
& & Min & Max & Average & SD & \\
\cline { 3 - 6 } of vation
\end{tabular}

a,b,c The same letters means lack of statistically significant differences (Fischer's LSD multiple range test, $p<0.05$ ). 
consisted of population No. 1 and 3. Under SMM model, no signature of bottleneck was visible for neither cluster 1 nor 2 .

\section{Relatedness}

The kinship coefficient infers about the level of relatedness between individuals, 0.5 for full-sibs, 0.25 for half-sibs, whereas 0.125 describes next degree of relatedness, e.g. between first cousins. The summary of the relatedness based on multilocus kinship coefficient $F_{i j}$ (LOISELLE et al., 1995) is presented in Table 5. The highest average value of $F_{i j}(0.0171)$ was found in northern population No. 1 , whereas the lowest $(0.0022)$ in population No. 6 from the central Sweden. Breeding population No. 9 from the south and No. 3 from the north were also characterized by higher than average value of $F_{i j}$, which were 0.0125 and 0.0123 , respectively. Result of Fischer's LSD multiple range test on $F_{i j}$ from each breeding population showed that populations No. 1, 3 and 9 had similar level of $F_{i j}$ that is significantly higher than those of populations No. 2 and 4-7. We also estimated all pairwise $F_{i j}$ values between all 456 individuals, the general tendency was that individuals from the same stand have slightly higher kinship coefficient, although not significant, as relative to individuals between stands and populations. The results of Mantel test showed that the linear relationship between estimated kinship coefficient between pairs of individuals and their geographic distance was not significant $\left(\mathrm{R}^{2}=0.0045, p=0.9999\right)$. Relatedness analyses performed on the BAPS clusters indicated a significantly higher $F_{i j}$ in cluster $1(0.0149)$ than in cluster $2(0.0012)$.

\section{Discussion}

Genetic diversity and structure in northern Swedish spruce populations

Analyses of nine breeding populations of Norway spruce from Sweden revealed high levels of genetic diversity and low differentiation among populations. Both $F_{S T}$ and AMOVA showed that only $0.87 \%$ of observed variance is explained by differences among populations. This partition of genetic variation is in agreement with the general pattern observed in outcrossing and wind pollinated conifers (HAMRICK et al., 1992; WANG and SzMIDT, 2001). Earlier studies on this species using allozymes have found $4.4 \%$ differentiations (in $\mathrm{G}_{\mathrm{ST}}$ ) in local populations from Switzerland and Italy (GianNini et al., 1991; MÜLler-STARCK, 1995), and up to $5.2 \%$ for the whole European range (LAGERCRANTZ and RYMAN, 1990). Using nuclear SSR markers, a level of differentiation of $2.9 \%$ is reported in northern Europe (TOLlefsRud et al., 2009). The highest $F_{S T}=0.118$ is reported for relict mountainous populations from Italian Alps (ScotTi et al., 2000). The low divergence in the Swedish populations could be due to several factors such as recent population establishment, homogenous landscape, continuous distribution and thus extensive pollen flow, and the relatively small geographic scale of our survey. Extensive gene flow promotes high levels of genetic diversity within populations and low interpopulation differentiation and counteracts negative effects of genetic drift or directional selection on diversity (BURCZYK et al., 2004).

Although differentiation is low among the analysed populations, two genetic clusters were recognized by BAPS which distinguished the two northern most populations (Nos. 1 and 3) from the rest. PCA based on allele frequencies also revealed distinct characters of these two northern populations. Additionally, one population (No. 2) from the central west and two from the south (Nos. 8 and 9) were also distinct on the PCA space. This geographical subdivision among the analysed populations seems reflect the postglacial migration routes of the species in Scandinavia peninsula. One of the putative refugia of Norway spruce during the last glaciations was in western Russia from which the species expanded westwards to the Baltic region and Finland, and then one route went northwest along the shore of Gulf Bothnia and afterwards to Norway and Sweden (HuntLeY and BiRKs, 1983; SchMidT-Vogt, 1977; TOLlefsRUd et al., 2008). Other migration routes, as indicated by mtDNA (TOLLEFSRUd et al., 2008) and macrofossil records (KULLMAN, 2008), includes west or southwestern migration across the Baltic Sea, which lead Norway spruce to the southern Scandinavia. A more recent study (PARDUCCI et al., 2012) based on ancient DNA further suggested another refugia of Norway spruce in western Norway during the glacial times, which expanded south- and eastward and eventually mixed with populations arriving from the east. The two northernmost populations (Nos. 1 and 3) in our study are located on the northwestern route from where Norway spruce entered Scandinavian Peninsula, and they appeared as a distinct genetic unit. The same genetic structure is also observed by Tollefsrud et al. (2009) and CHEN et al. (2012), which identified the northern European range of Norway spruce as a cluster of populations differentiated from the central Scandinavia. These two populations showed sign of bottleneck under IMA model as indicated by an excess of heterozygotes, which may reflect either their population history in the region or gene flow from genetically more variable populations (LAGERCRANTZ and RYMAN, 1990). The unique position of population No. 2 was unexpected, but in light of recent proposal of western Norway refugia (PARDUCCI et al., 2012), this population might represent an admixture from that route, a hypothesis though needs more sampling to be validated. The little differentiated cluster from mid Sweden likely represents another postglacial establishment via seeds and pollen from terrains of present Finland across the relatively narrow gulf.

The observed differentiation between northern and central populations could also be influenced by factors that shape more recent gene flow, e.g. differences in flowering phenology or pollen productivity. Compared to southern localities northern stands of Norway spruce have later anthesis (LUOMAJOKI, 1993). Meteorological data show more frequent winds from south or southeast directions in both southern and northern Sweden (BERGSTRÖm and SöDERBERG, 2008). These are responsible for mostly northward direction of pollen mediated gene flow. As an effect genetically more homogeneous populations of Norway spruce could be observed in cen- 
tral Sweden. Towards the northern limit, spruce flowering and pollen production become limited, and flowering season is later (LUOMAJOKI, 1993). These factors may restrict effective pollen flow between northern and central regions of Sweden, and provide a barrier that maintains genetic structure shared by geographically close and phenologically similar northern populations.

In southern Sweden, non-autochthonous stands of Norway spruce have been planted in the past century (HANNERZ and HANELL, 1997; JoHANN, 2004). Emergence of non-native Norway spruce populations in southern Sweden is associated with intensive silviculture and increased need for seeds for new forest plantations. Provenances from Baltic states and continental Europe are used in production forests (HANNERZ and HANELL, 1997), which introduced central European haplotypes or alleles of P. abies to southern Sweden (CHEN et al., 2012; SPERISEN et al., 1998). Therefore, the observed divergence in the most southern breeding populations investigated in this study (Nos. 8 and 9) could be explained by the admixture of alleles of non native origin.

In conclusion, our data showed that the genetic variation of Norway spruce in Northern Sweden is shaped by the recolonization after the last glaciations. Variations in current gene flow and silviculture activities have also an influence on the genetic structure of the species. Therefore, the observed pattern of genetic differentiation of the species in Sweden reflects a dynamic system which still evolves following both natural and artificial processes.

Genetic status of the Swedish spruce breeding population and implication for long-term breeding and conservation

The goal of the Swedish spruce breeding program is to produce adequate quantity of superior material for reforestation while maintaining high genetic variation to assure progress in targeted traits for many generations (JOHNSON and LIPOW, 2002; LINDGREN, 2009). Currently, about half of the Norway spruce plantations in Sweden originate from seed orchards (LINDGREN, 2009). Each seed orchard is intended to produce seeds for specific deployment area, which are defined by the origin of the parents and the growth rhythm and hardiness performance of the orchard offspring. Genetic evaluation of the breeding stock combined with information gained from progeny and clonal tests, where quantitative traits describing phenotypic variation, adaptation to climatic conditions and disease resistance are measured (PERSSON and PERsson, 1992 ), is essential for accurate estimation of genetic value of the breeding material and for predicting the gain and diversity in future spruce forestry.

Studies of neutral variation that reveal genetic diversity and genetic subdivision of the species throughout its geographical range provide information about mating systems, population migrations and colonization patterns. On the other hand, analyses of variation in quantitative and adaptive traits give a better understanding of the population potential and plasticity in response to specific environmental conditions. As these two approaches provide different kinds of information, understanding of both aspects of diversity is essential for the development of appropriate breeding and gene conservation strategies. Our analysis using nuclear SSRs showed high genetic diversity in the nine spruce breeding populations, a property highly desirable for any breeding program since it assures more progress can be expected from the resulting production forest combined with desirable variation. However, we did not find any correspondence between SSR variation in the analyzed populations and the breeding zone division. We found that the nine breeding populations can be divided into two slightly differentiated groups: one consists of the two northernmost populations, and the other with all the remaining seven. This pattern of genetic differentiation reflects the recolonization history of the spruce in Scandinavia, which is maintained despite of intensive inter-site gene flow. This observation has some implications for planning breeding activities when it may be necessary to consider if the distinguished northern group should or should not be mated with the more genetically homogenized populations from central Sweden, or be considered in separate seed orchard deployment program.

Apart from maintaining a high level of genetic diversity, long-term breeding populations must also be characterized by low level of relatedness to avoid inbreeding in planted forests and to sustain diversity for future generations. The estimated relatedness of the trees gathered in the breeding populations seems to be very low and not structured. The estimation of inbreeding coefficient in each population indicated heterozygote deficiency, but after removing loci with high null allele frequencies the average inbreeding in the nine populations became 0.089 . This level of inbreeding is within the range reported for natural populations of the species within European range (-0.17 to 0.174) (LAGERCRANTZ and RYMAN, 1990) and in Polish provenances (0.057 to 0.90) (LEWANDOWSKI and BURCZYK, 2002). However, our estimates are noticeably lower than those previously reported for northern European populations (0.121 to 0.346) (TollefsRUd et al., 2009). This difference could be due to variations in null alleles at different loci and their treatment in estimation of genetic parameters among studies.

Norway spruce is a predominantly outcrossing species, thus inbreeding includes not only selfing, which is considered to be rather low (BURCZYK et al., 2004; SHIMONo et al., 2010), but also mating among relatives within stands. The reduction in effective number of outcross males is one of the plausible explanations for the rise in inbreeding rate in marginal populations (BURCZYK et al., 2004). Analyses of spatial variation in pollen flow show that in case of Norway spruce effective pollen dispersal decrease rapidly with the distance from the pollen source and on the local scale follows leptokurtic distribution within $30 \mathrm{~m}$ radius (SHIMONo et al., 2010). This mating pattern within a stand implies that despite much of fertilizing pollen come from long distances, mating among close neighbouring trees may results in building up spatial genetic structure in offspring, even though the genetic structure among adult trees is absent. On the other hand, the short effective pollen dispersal also means a significant decrease of 
relatedness between offspring with increasing distance between their mother trees. The selection of plus trees for breeding follows regulations such as restricted selections from a stand and sufficient spatial distance (usually at least $100 \mathrm{~m}$ ) separating them. Therefore, it is not surprising that rather low values of inbreeding coefficient and relatedness characterized the trees in the analysed breeding populations. Low level of relatedness among individuals implies that it will be possible to structure a sustainable long term breeding with limited inbreeding and to construct production populations that suffer little from inbreeding depression, which generally expresses as reduced fitness, lower survival and growth (ERIKSSON et al., 1973; SKRøPPA, 1996). In Sweden, seed orchards are established with these unrelated founders selected from different stands. Inbreeding and inbreeding depression in orchard produced forest regeneration materials should be lower compared to the natural forest. If high inbreeding (LAGERCRANTZ and RYMAN, 1990; LEWANDOWSKI and BURCZYK, 2002; TOLLEFSRUD et al., 2009) is a general feature in northern spruce populations, then the gain from the breeding program is even higher than earlier anticipated, and the selected founder populations comprise a good support for long-term breeding of Norway spruce in Sweden.

In conclusion, our evaluation of the Swedish spruce breeding populations revealed high genetic diversity and low relatedness for materials within each breeding population and in the whole collection. Genetic variation and relatedness are two special concerns of long-term breeding programs. High genetic variation and low coancestry are desired in founder populations to support gain and adaptation of production forest to environmental changes during future generations. The analysed Norway spruce collection constitutes a good sample of the natural variation and can be considered as a good foundation for this purpose. These superior genotypes are being evaluated in combined clonal and progeny tests. Apart from being high in breeding values, they also represent valuable genetic resources for conservation of natural variation of Norway spruce in northern Sweden. The lack of fine-scale genetic structure in the breeding populations makes it likely that the selections cover most of the existing natural variation and wider sampling for breeding is not needed. This knowledge and collection may become important for both breeding and conservation purposes which must consider not only timber, but also the whole range of resource values of a forest ecosystem including the ecological and social benefits.

\section{Acknowledgements}

This study was supported by grants from the Swedish Association of Forest Tree Breeding, the Bo Rydins Stiftelse, and Formas, Sweden.

\section{References}

Bergström, H. and S. SöDerberg (2008): Wind Mapping of Sweden. Summary of results and methods used. Elforsk rapport 09:04.
Besnard, G., V. Achere, P. F. Rampant, J. M. FaVre and S. JEANDROZ (2003): A set of cross-species amplifying microsatellite markers developed from DNA sequence databanks in Picea (Pinaceae). Mol. Ecol. Notes 3: 380-383.

BurczyK, J., A. LewANdowski and W. ChalupkA (2004): Local pollen dispersal and distant gene flow in Norway spruce (Picea abies [L.] Karst.). For. Ecol. Manage. 197: 39-48.

Chapuis, M. P. and A. Estoup (2007): Microsatellite null alleles and estimation of population differentiation. Mol. Bio. Evol. 24: 621-631.

Chen, J., T. Kallman, X. F. Ma, N. Gyllenstrand and G. ZAINA et al. (2012): Disentangling the roles of history and local selection in shaping clinal variation of allele frequencies and gene expression in Norway spruce (Picea abies). Genetics 191: 865-U377.

Corander, J., P. Marttinen, J. Siren and J. Tang (2008): Enhanced Bayesian modelling in BAPS software for learning genetic structures of populations. BMC Bioinformatics 9.

CoRnuet, J. M. and G. Luikart (1996): Description and power analysis of two tests for detecting recent population bottlenecks from allele frequency data. Genetics 144: 2001-2014.

Dempster, A. P., N. M. LAIRD and D. B. Rubin (1977): Maximum likelihood from incomplete data via EM algorithm. J. R. Stat. Soc. Ser. B-Methodol. 39: 1-38.

ERIKsson, G., B. Scheland and V. Akebrand (1973): Inbreeding depression in an old experimental plantation of Picea abies. Hereditas 73: 185-194.

Evanno, G., S. Regnaut and J. Goudet (2005): Detecting the number of clusters of individuals using the software STRUCTURE: a simulation study. Mol. Ecol. 14: 2611-2620.

Excoffier, L., G. LAVAL and S. SCHNEIDER (2005): Arlequin (version 3.0): An integrated software package for population genetics data analysis. Evol. Bioinform. 1: 47-50.

Giannini, R., M. Morgante and G. G. Vendramin (1991): Allozyme variation in Italian populations of Picea abies (L.) Karst. Silvae Genet. 40: 160-166.

Guo, S. W. and E. A. Thompson (1992): Performing the exact test of Hardy-Weinberg proportions for multiple alleles. Biometrics 48: 361-372.

Hamrick, J. L., M. J. W. Godt and S. L. Sherman-Broyles (1992): Factors influencing levels of genetic diversity in woody plant species. New For. 6: 95-124.

HANNERZ, M. and B. HANELL (1997): Effects on the flora in Norway spruce forests following clearcutting and shelterwood cutting. For. Ecol. Manage. 90: 29-49.

HARDY, O. J. and X. VEKEMANS (2002): SPAGeDi: a versatile computer program to analyse spatial genetic structure at the individual or population levels. Mol. Ecol. Notes 2: 618-620.

Hodgetts, R. B., M. A. Aleksiuk, A. Brown, C. Clarke and E. MACDONALD et al. (2001): Development of microsatellite markers for white spruce (Picea glauca) and related species. Theor. Appl. Genet. 102: 1252-1258.

Huntley, B. and H. J. B. BiRKs (1983): An atlas of past and present pollen maps for Europe: 0-13000 years ago. Cambridge University Press. Cambridge, U.K.

JoHANN, E. (2004): History of secondary Norway spruce forests in Europe. In: Norway spruce conversion: options and consequences, edited by H. SPIECKER, J. Hansen, E. Klimo, J. P. Skovsgaard, H. Sterba and K. Von Teuffel. Brill Academic Publishers. 
Johnson, R. and S. LIPOW (2002): Compatibility of breeding for increased wood production and longterm sustainability: the genetic variation of seed orchard seed and associated risks, pp. 169-179. In: Congruent management of multiple resources, Proceedings from the Wood Compatibility Initiative Workshop 18, edited by A. Johnson, R. Haynes and R. Monserud. General Technical Report PNW-GTR-563. Portland, OR, USA: U.S. Department of Agriculture, Forest Service, Pacific Northwest Research Station.

KULLMAN, L. (2008): Early postglacial appearance of tree species in northern Scandinavia: review and perspective. Quat. Sci. Rev. 27: 2467-2472.

LAGERCRANTZ, U. and N. RYMAN (1990): Genetic structure of Norway spruce (Picea abies): concordance of morphological and allozymic variation. Evolution 44: 38-53.

LEwANDOwski, A. and J. BuRCZYK (2002): Allozyme variation of Picea abies in Poland. Scand. J. Forest Res. 17: 487-494.

LindGren, D. (2009): Picea abies breeding in Sweden is based on clone testing. Dendrobiology 61: 79-82.

Lindgren, D., B. Karlsson, B. Andersson and F. PreschER (2008): The Swedish seed orchard program for Scots pine and Norway spruce, pp. 142-154. In: Proceedings of Seed Orchard Conference. 26-28 September 2007, Umeå, Sweden. Edited by D. LINDGREN, Department of forest genetics and plant physiology, Swedish University of Agricultural Sciences.

Loiselle, B. A., V. L. Sork, J. Nason and C. Graham (1995): Spatial genetic structure of a tropical understory shrub, Psychotria officinalis (Rubiaceae). Am. J. Bot. 82: $1420-1425$.

LUOMAJOKI, A. (1993): Climatic adaptation of Norway spruce (Picea abies (L.) Karsten) in Finland based on male flowering phenology. Acta Forestalia Fennica 242: 28.

Mimura, M. and S. N. AitKen (2007): Increased selfing and decreased effective pollen donor number in peripheral relative to central populations in Picea sitchensis (Pinaceae). Am. J. Bot. 94: 991-998.

MÜLlER-STARCK, G. (1995): Genetic variation in high elevated populations of Norway spruce (Picea abies (L) Karst) in Switzerland. Silvae Genet. 44: 356-362.

Müller-Starck, G., P. Baradat and F. BergmanN (1992): Genetic variation within European tree species. New For. 6: 23-47.

Parducci, L., T. Jorgensen, M. M. Tollefsrud, E. ElverLAND and T. AlM et al. (2012): Glacial survival of boreal trees in Northern Scandinavia. Science 335: 1083-1086.

Peakall, R. and P. E. SMouse (2006): GENALEX 6: genetic analysis in Excel. Population genetic software for teaching and research. Mol. Ecol. Notes 6: 288-295.

Persson, A. and B. Persson (1992 ): Survival growth and quality of Norway spruce (Picea abies L.) Karst.) provenances at the three Swedish sites of the IUFRO 1964-68 provenance experiment. Department of Forest Yield Research, Swedish University of Agricultural Sciences.

Pfeiffer, A., A. M. Olivieri and M. Morgante (1997): Identification and characterization of microsatellites in Norway spruce (Picea abies K.). Genome 40: 411-419.

Piry, S., G. LuikarT and J. M. CoRnuet (1999): BOTTLENECK: A computer program for detecting recent reductions in the effective population size using allele frequency data. J. Hered. 90: 502-503.
Pritchard, J. K., M. Stephens and P. Donnelly (2000): Inference of population structure using multilocus genotype data. Genetics 155: 945-959.

RAJora, O. P., A. Mosseler and J. E. MAJor (2002): Mating system and reproductive fitness traits of eastern white pine (Pinus strobus) in large, central versus small, isolated, marginal populations. Can. J. Bot. 80: 1173-1184.

RICE, W. R. (1989): Analyzing tables of statistical tests. Evolution 43: 223-225.

RoBledo-ARnuncio, J. J., R. AliA and L. Gil (2004): Increased selfing and correlated paternity in a small population of a predominantly outcrossing conifer, Pinus sylvestris. Mol. Ecol. 13: 2567-2577.

ROUSSET, F. (2008): GENEPOP'007: a complete re-implementation of the GENEPOP software for Windows and Linux. Mol. Ecol. Resour. 8: 103-106.

Schmidt-Vogt, H. (1977): Die Fichte, Band 1. Verlag Paul Parey, Hamburg.

Scotti, I., F. Magni, G. P. Paglia and M. Morgante (2002a): Trinucleotide microsatellites in Norway spruce (Picea abies): their features and the development of molecular markers. Theor. Appl. Genet. 106: 40-50.

Scotti, I., G. P. Paglia, F. Magni and M. Morgante (2002b): Efficient development of dinucleotide microsatellite markers in Norway spruce (Picea abies Karst.) through dot-blot selection. Theor. Appl. Genet. 104: 1035-1041.

Scotti, I., G. G. Vendramin, L. S. Matteotti, C. Scarponi and M. SARI-Gorla et al. (2000): Postglacial recolonization routes for Picea abies K. in Italy as suggested by the analysis of sequence-characterized amplified region (SCAR) markers. Mol. Ecol. 9: 699-708.

Shimono, A., X.-R. WANG, T. Torimaru, D. Lindgren and B. KARLSSON (2010): Spatial variation in local pollen flow and mating success in a Picea abies clone archive and their implications for a novel "breeding without breeding" strategy. Tree Genet. Genomes 7: 499-509.

SKOGFORSK (2011): Review of the Swedish tree breeding programme. http://www.skogforsk.se.

SkrøPPA, T. (1996): Diallel crosses in Picea abies, 2: Performance and inbreeding depression of selfed families. For. Genet. 3: 69-79.

SPERISEN, C., U. BÜChLER and G. MÁtYÁs (1998): Genetic variation of mitochondrial DNA reveals subdivision of Norway spruce (Picea abies (L.) Karst.), pp. 413-417. In: Molecular tools for screening biodiversity. Plant and animals. Edited by A. KARP, P. G. ISAAC and D. S. INGRAM. Chapman \& Hall, London.

STATSOFT, I. (2005): STATISTICA (data analysis software system), version 7.1. www.statsoft.com.

Tollefsrud, M. M., R. Kissling, F. Gugerli, O. Johnsen and T. SKRopPa et al. (2008): Genetic consequences of glacial survival and postglacial colonization in Norway spruce: combined analysis of mitochondrial DNA and fossil pollen. Mol. Ecol. 17: 4134-4150.

Tollefsrud, M. M., J. H. Sonstebo, C. Brochmann, O. Johnsen and T. Skroppa et al. (2009): Combined analysis of nuclear and mitochondrial markers provide new insight into the genetic structure of North European Picea abies. Heredity 102: 549-562.

WANG, X.-R. and A. E. SzMidT (2001): Molecular markers in population genetics of forest trees. Scand. J. Forest Res. 16: 199-220.

Weir, B. S. and C. C. Cockerham (1984): Estimating $F$-statistics for the analysis of population structure. Evolution 38: 1358-1370. 